\title{
Neuropeptides of the autonomic nervous system in Sjögren's syndrome
}

Centre of Caring Science North, Department of Medicine, Karolinska Hospital, Stockholm, Sweden

N Santavirta

H Björvell

Institute of

Biomedicine, Department of

Anatomy, University of Helsinki, Helsinki,

Finland

J Törnwall

Research Unit ORTON, Invalid Foundation, Helsinki, Finland

M Segerberg

Division of Rheumatic Diseases, Department of Medicine, Helsinki University Central Hospital, Finland Y T Konttinen

Department of Orthopaedics and Traumatology, Helsinki University Central Hospital, Finland

S Santavirta

Institute of Internal Medicine, University of Cagliari, Italy M Matucci-Cerinic

Correspondence to: Dr Y T Konttinen, Institute of Biomedicine, Department of Anatomy, University of Helsinki, PO Box 9 (Siltavuorenpenger 20 A), FIN-00014, Finland.

Accepted for publication 18 September 1997

Nina Santavirta, Yrjö T Konttinen, Jyrki Törnwall, Margaretha Segerberg, Seppo Santavirta, Marco Matucci-Cerinic, Hjördis Björvell

\begin{abstract}
Objective-To assess the activity level of the autonomic nervous system in Sjögren's syndrome (SS) and to correlate this with stress.

Methods-Patients with SS $(\mathrm{n}=12)$ and healthy controls $(n=10)$ were analysed for the content of vasoactive intestinal peptide (VIP) and neuropeptide Y (NPY) in their stimulated saliva by radioimmunoassays and for stress by the use of a modified Jenkins Activity Survey (JAS).

Results-The data are expressed as median (interquartile range). Salivary VIP output (pg/min) and NPY output (pg/min) were high in SS compared with healthy controls $(30.0(15.6,36.6)$ versus $12.3(9.2$, 24.0), $\mathrm{p}=0.045,4.8(0.6,24.1)$ versus 0.7 $(0.0,2.4), p=0.038$, respectively). Patients experienced only a little, but not significantly, more stress than the healthy controls (stress index $-2.8(-7.7,6.9)$ versus $-5.2(-12.9,2.7), p>0.05)$. Stress in general was associated with high salivary VIP concentrations $(r=0.41, p=0.05)$.

Conclusions-These findings show that adequately processed saliva (containing aprotinin and EDTA as neuropeptidase inhibitors) contains measurable amounts of marker peptides of the autonomic nervous system. Secondly, VIP concentration but not output may be affected by stress, which may act by decreasing watery salivary flow. In patients with SS, VIP and NPY outputs are increased. This may indicate increased leakage into saliva or efforts to compensate for the diminished salivary flow, or both.
\end{abstract}

(Ann Rheum Dis 1997;56:737-740)

Sjögren's syndrome (SS) is a systemic autoimmune disease characterised by exocrinopathy of unknown aetiology and pathogenesis leading to dry mouth (xerostomia) and dry eyes (keratoconjunctivitis sicca). A particularly prominent and diagnostically useful feature is focal adenitis, which develops in both salivary and lacrimal glands. ${ }^{1-3}$ For practical reasons focal adenitis is usually diagnosed from labial salivary gland biopsy specimens. ${ }^{4}$ This focal sialadenitis is associated with decreased resting salivary flow (according to the European criteria $\leqslant 0.1 \mathrm{ml} / \mathrm{min}) .^{35}$

There is a remarkable discrepancy between the focal and often relatively mild glandular involvement in form of adenitis (with patho- logical focus score values $\geqslant 1$ often affecting less than $10 \%$ of the total area, except in far advanced end stage cases) and the considerably decreased salivary flow $(\leqslant 0.1 \mathrm{ml} / \mathrm{ml}$ of whole resting salivary flow-that is, about only $10 \%$ of the normal salivary production). One explanation, which has recently been put forward, is that this autoimmune disorder as such or as a result of focal adenitis leads to vasoneural dysregulation and injury of the peripheral nerve fibres and thus to diminished salivary flow and atrophy of the acinar cells. ${ }^{67}$ It has been widely accepted that normal salivary flow is under neural regulation: parasympathetic stimulation increases salivary flow, whereas stressful stimuli decrease it via central sympathetic activation. ${ }^{8}$ Accordingly, a parasympathomimetic drug, pilocarpine, has been found useful in the treatment of dry mouth ${ }^{9-12}$ and electrostimulation, which augments normal physiological salivary reflexes, stimulates production of saliva in SS. ${ }^{13}$ The aim of the study was therefore to measure the salivary content of vasoactive intestinal peptide (VIP) and neuropeptide Y (NPY), which in labial salivary glands are found mainly in the parasympathetic and sympathetic arm, respectively, of the autonomic nervous system. Activity of the autonomic nervous system is influenced by the somatic well being, in particular by the degree of stress. ${ }^{14}$ In fact, dry mouth associated with depression and anxiety or the treatment with psychotropic drugs (with anticholinergic side effects), or both, is one of the most important differential diagnostic alternatives in Sjögren's syndrome clinics. We therefore also aimed to measure stress by using a modified Jenkins Activity Survey (JAS) to correlate it with the degree of sympathetic and parasympathetic activity.

\section{Methods}

PATIENTS AND CONTROLS

Twelve female patients with chronic established SS were studied; all fulfilled the European Classification Criteria for SS. ${ }^{5}$ Primary SS was diagnosed if any four of the six classification criteria are fulfilled. Secondary SS is diagnosed if there is a positive response to items 1 or 2 (ocular symptoms or oral symptoms), plus a positive response to at least two items from among 3, 4, and 5 (ocular signs, histopathological features, salivary gland involvement). In both cases, the adequate exclusions (sarcoidosis, lymphoma, aquired immunodeficiency syndrome and graft versus host disease) were done. Ten healthy female volunteers served as controls. 
The average age of the SS patients was 47.5 (range 21-59) years. The duration of the SS was on average 8.6 (range 1-17) years. All the patients were non-smokers. Five of the patients were married, three unmarried, and four divorced. Three of them worked in a white collar profession, four in a blue collar profession, one was a college student, and four were retired because of the disease.

The average age of the 10 healthy controls was 47.7 (range 39-56) years. Six of them were married, one was engaged to be married, two were divorced, and one was a widow. Nine of the controls were blue collar workers in a health care profession and one was a cleaning woman. Eight of them were non-smokers, one smoked 5-20 cigarettes a day, and another smoked more than 20 cigarettes.

RADIOIMMUNOASSAY

Both the patients and the controls gave a stimulated salivary sample as described elsewhere. ${ }^{15}$ The stimulated whole saliva was collected for 15 minutes. The stimulus used was chewing a piece of hard paraffin. The saliva samples were collected to chilled tubes containing $50000 \mathrm{IU} / \mathrm{ml}$ aprotinin and $10 \mathrm{mM}$ EDTA to minimise artefactual neuropeptide degradation in vitro and stored at $-40^{\circ} \mathrm{C}$ until analysed. ${ }^{15}$

Neuropeptide concentration in saliva was measured using a standard competetive ${ }^{125} \mathrm{I}-$ radioimmunoassay kit (Peninsula, Belmont, CA, USA). Briefly, (1) $100 \mu$ of sample or standard was incubated in polypropylene tubes for 24 hours at $+4^{\circ} \mathrm{C}$ with $100 \mu \mathrm{l}$ rabbit antihuman VIP or NPY IgG, (2) $100 \mu \mathrm{l}$ of ${ }^{125} \mathrm{I}-$ labelled peptide $(10000-15000 \mathrm{cpm} / 100 \mu \mathrm{l})$ was added and incubated for 24 hours at $+4^{\circ} \mathrm{C}$, (3) $100 \mu \mathrm{l}$ goat antirabbit IgG and 100 $\mu \mathrm{l}$ normal rabbit serum were added and incubated for 90 minutes at room temperature before (4) $500 \mu \mathrm{l}$ RIA buffer was added followed by centrifugation at $1700 \mathrm{~g}$ for 20 minutes at $+4^{\circ} \mathrm{C}$; supernatant was disregarded and the radioactivity of the pellet was measured with a programmed gamma scintillation counter. Rabbit antihuman VIP antibodies show no cross reactivity with human PHM-27 (peptide histidine methionine), substance P, VIP 1-12, endothelin-1, glucagon, somatostatin, PACAP-38 (pituitary adenylate cyclase activating peptide), PACAP-38 (1638 ), porcine secretin or rat galanin and less than $0.02 \%$ cross reactivity with human PACAP-27. Similarly, rabbit antihuman NPY antibodies show no cross reactivity with human pancreatic polypeptide, VIP, amylin, prepro NPY 68-97, insulin or somatostatin. All samples were analysed in duplicate with individual controls for apparent binding in the absence of antibody (that is, total counts, nonspecific binding, total binding).

JENKINS ACTIVITY SURVEY

The JAS scale consists of 84 items that are divided in four subscales. For this study we recorded the values of the actual A-B factor with 21 items, which best reflect the stress behaviour of a person. ${ }^{16}$
The study was carried out according to the principles of the Declaration of Helsinki, and with the approval of the ethical committees of the institutions involved. The BMDP software package version 7.0. was used for the statistical analysis. ${ }^{17}$ The data are expressed as median (interquartile range). The comparison between the patients and the healthy controls was performed with the use of the Mann-Whitney test. The difference in variability between samples was tested by Siegel-Tukey test when there was no difference in median and by Moses rank-like test when there was a difference. The correlation between stress and salivary neuropeptide content was studied with the use of the Spearman's rank correlation coefficient. The reliability of the stress factor was measured with the use of the Cronbach alpha test. ${ }^{18}$

\section{Results}

SALIVARY FLOW RATE

There was no significant difference in the median between the stimulated flow rate $(\mathrm{ml} / \mathrm{min})$ of the SS patients and the healthy controls $(0.4 \quad(0.2-0.7) \quad v \quad 0.4 \quad(0.3-0.4)$, $\mathrm{p}=0.304)$, but there was a significant difference in the variability between the flow rate values of the groups ( $p=0.0018$ ) (fig 1 ).

SALIVARY VIP AND NPY

Salivary VIP output ( $\mathrm{pg} / \mathrm{min}$ ) was high in SS compared with healthy controls (30.0 (15.6$36.6) v 12.3(9.2-24.0), \mathrm{p}=0.045)$ with no difference in variability $(\mathrm{p}=0.11)$ (fig 2$)$. Salivary VIP concentration $(\mathrm{pg} / \mathrm{ml})$ was higher in SS compared with healthy controls (66.2 (50.272.6) v 33.6 (22.6-64.8), $\mathrm{p}=0.025)$. There was no significant difference when expressed per mg protein or content (22.4 (18.1-30.6) $v 15.2$ (7.7-38.2), $p>0.05)$. The concentration and content of salivary VIP in the two smokers were numerically below the average of the other healthy controls.

Salivary NPY output (pg/min) was high in SS compared with healthy controls (4.8 $(0.6-24.1)$ v $0.7(0.0-2.4), \mathrm{p}=0.038)$, also there was significant difference in variability $(\mathrm{p}=0.016)$ (fig 3). Salivary NPY concentration $(5.4(1.2-76.0) \mathrm{pg} / \mathrm{ml} v 2.1(0.0-7.1) \mathrm{pg} / \mathrm{ml})$

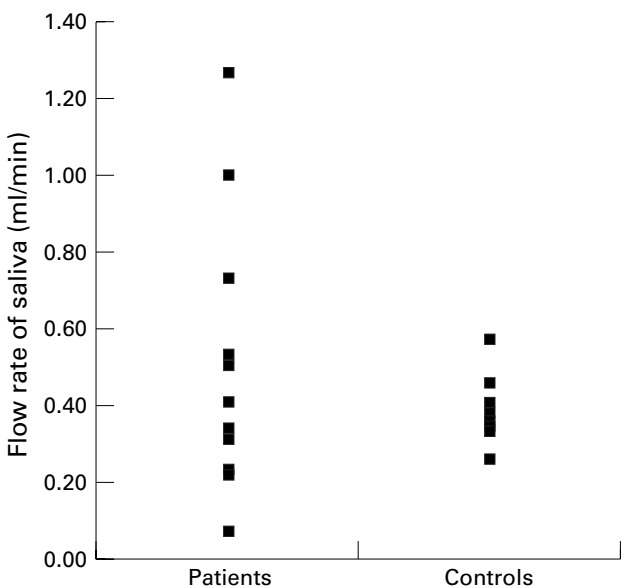

Figure 1 Dot plot of the flow rate of saliva ( $\mathrm{ml} / \mathrm{min}$ ) for SS patients and healthy controls. 


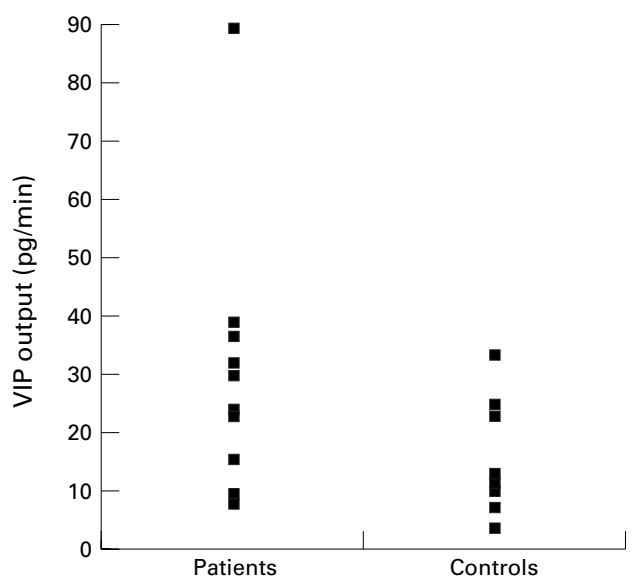

Figure 2 Dot plot of the VIP output (pg/min) for SS patients and healthy controls.

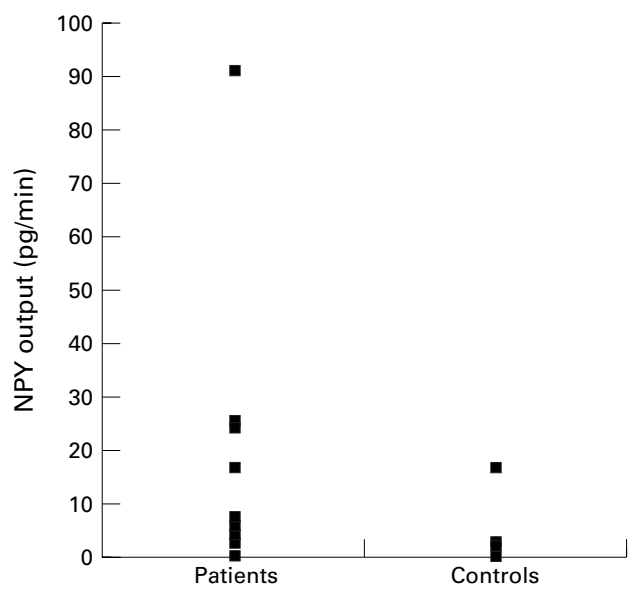

Figure 3 Dot plot of the NPY output (pg/min) for SS patients and healthy controls.

and content (pg/mg protein: $2.3(0.6-27.3) v$ 2.7 (1.6-4.4)) did not significantly differ in SS and in healthy controls and there were no differences in variability. NPY contents in the two smokers were similar to NPY values in other healthy controls.

JAS

The reliability of the type A-B factor was tested with the use of the Cronbach alpha coefficient (alpha $=0.51)$ and on basis of this calculation, five of the original 21 items were omitted. After omission of these factors, the alpha coefficient improved to 0.63 . However, also when the corrected mean value for the A-B type factor was used, the patient group $(-2.8(-7.7,6.9)) \mathrm{did}$ not differ significantly from that of the control group $(-5.2(-12.9,2.7) ; \mathrm{p}>0.05)$. The duration of the patients' disease history, the severity of the general disease symptoms (joint pain and fatigue), the severity of local symptoms (symptoms of the eyes, dryness of the mouth), and the patients' age were not significantly related to the value of the A-B factor.

CORRELATION BETWEEN SALIVARY

NEUROPEPTIDES AND STRESS

In the whole material, there were no significant correlations between stress (as expressed by the JAS factor A-B type behaviour) and the output of the neuropeptides. In the whole series, stress score (as expressed by the JAS factor A-B type behavior) correlated significantly with both VIP concentration ( $\mathrm{pg} / \mathrm{ml}, r=0.41, \mathrm{p}=0.05)$ and content ( $\mathrm{pg} / \mathrm{mg}$ protein, $r=0.53, \mathrm{p}=0.02)$. Thus, the more stress, the higher the VIP values. The correlation between NPY concentration or content and stress did not quite reach significance $(r=0.25, \mathrm{p}>0.05 ; r=0.33, \mathrm{p}>0.05)$.

When all study subjects were subdivided into patients and controls, it was found that in the patient group there were no significant correlations between the stress score and VIP values in the saliva, although there was a significant correlation between the stress score and the NPY concentration $(r=0.66, \mathrm{p}=0.02)$. There were positive, but not statistically significant, correlations in the healthy controls between the stress score and the VIP content and the VIP output $(r=0.52, \mathrm{p}>0.05 ; r=0.54, \mathrm{p}>0.05$ respectively).

\section{Discussion}

SS is characterised by sialopenia/xerostomia. It is the resting salivary flow, however, which is low. Stimulated salivary flow varies a lot between patients and may be normal. It has therefore not been included in the European Classification criteria. As a matter of fact, many patients use sialogogic stimuli, mechanical (such as a xylitol chewing gum) or chemical (such as pilocarpin) to alleviate their symptoms. In advanced or difficult cases, or both, stimulated salivary flow/reserves are low, but in many series including newly diagnosed patients stimulated salivary flow is normal. This was also the case in our series.

VIP is a 28 amino acid peptide, which belongs to the family of brain-gut peptides. ${ }^{19}$ In salivary glands it often colocalises with choline acetyltransferase and seems therefore to be useful as a peptide marker for postganglionic parasympathetic fibres in that tissue.$^{20} \mathrm{NPY}$ is a 36 amino acid peptide of the NPY/CPON family. ${ }^{21}$ It usually colocalises with cytoplasmic tyrosine hydroxylase and intravesicular dopamine- $\beta$ hydroxylase, which are classic markers for postganglionic sympathetic nerves. ${ }^{22}$ VIP and NPY are synthesised in the perikarya of the corresponding nerve cells in local parasympathetic ganglia, from where they are transported in an energy requiring fast axonal transport into nerve terminals to be stored there in dense core vesicles. In contrast with sensory nerves, postganglionic sympathetic and parasympathetic nerves display some spontaneous background activity, but large amounts of neuropeptides are released only after appropriate stimulation. ${ }^{23}$ Both VIP and NPY containing peptidergic nerves have been recently described in salivary glands in normal healthy controls and in patients with $\mathrm{SS}^{25}$

In this study the eventual release into and presence in saliva of VIP and NPY was assessed by RIA from saliva collected to a cocktail of enzyme inhibitors selected to prevent artefactual in vitro degradation by various neuropeptidases. Both neuropeptides were found in 
adequately processed samples suggesting local release and secretion to saliva.

After this first finding on the presence of VIP and NPY in saliva, eventual effects of disease and stress on their concentration were evaluated. These are often connected, because psychosocial features connected with chronic diseases contribute to psychic and somatic well being. ${ }^{26-28}$ The JAS instrument describes the persons's stress behaviour. The type A behavioural pattern comprises a cluster of actions and emotions exhibited by people who engage themselves in a chronic struggle and have a hyperresponsiveness to almost any challenge. ${ }^{28}$ These people are competitive with a driving need for control and an accentuated sense of time urgency. Changes in life style or circumstances as well as disease are known to modify the person's type A behavioural pattern. While stress may affect health, there is also evidence that a state of ill health, as was the case with our SS patients, can act as a significant source of stress in itself or can sensitise the person to other sources of stress by reducing their ability to cope. ${ }^{29}{ }^{30}$ Furthermore, at any point of time, the relation between stress and disease can operate in both directions, and may develop into a vicious cycle.

SS patients experienced on average slightly but not significantly more stress than the healthy controls as measured with the JAS instrument. According to the present findings, patients with SS seem to cope surprisingly well with their disease, at least as assessed by the extent of the stress they experience.

The physiological factors regulating VIP and NPY secretion are not known. In this study we found an interesting correlation between stress and salivary VIP concentration and content, but not VIP output. Stress might increase VIP release or, more probably, decrease the watery salivary flow. Stress may interfere with the normal salivary gland function finely controlled by coordinated and balanced excitatory and inhibitory inputs from tonically active postganglionic neurons. ${ }^{31}$

VIP has many different paracrine effects. It induces vasodilatation, modulates mast cell mediator release and lymphocyte migration and recirculation. ${ }^{62}$ In addition, VIP has important trophic effects on salivary gland acinar cells in the long term. ${ }^{7}$ According to recent immunoelectron microscopic studies published elsewhere, VIPergic fibres come into close contact with the acinar cells and some fibres are even located hypolemmally - that is, inside the acinar basement membrane. ${ }^{33} \mathrm{NPY}$ causes vasoconstriction, modulates neurotransmitter release from sensory and postganglionic sympathetic neurons, and up regulates adhesiveness of endothelial cells for leucocytes. According to this study, these neuropeptides are not only found in salivary glands, but are also released there and to some extent found in saliva; they might therefore contribute to the local pathomechanisms in SS.

This study was supported by the Victoria Foundation, the Signe and Ane Gyllenberg Foundation, Helsinki University Central and Ane Gyllenberg Foundation, Helsinki University Central for Rheumatology and Invalid Foundation.
1 Strand V, Talal N. Advances in the diagnosis and concept of Sjögren' syndrome (autoimmune exocrinopathy). Bull Sjögren' syndrome (autoimm

2 Fox RI, Howell FV, Bone RC, Michelson P. Primary Sjögren' syndrome: clinical and immunopathological features. Semin Arthritis Rheum 1984:14:77-105.

3 Manthorpe R, Oxholm P, Prause JU, Schiødt M. The Copenhagen criteria for Sjögren' syndrome. Scand J Rheumatol 1986; suppl 61:19-21.

4 Daniels TE. Labial salivary gland biopsy in Sjögren' syndrome. Arthritis Rheum 1984:27:147-56

5 Vitali C, Bombardieri S, Moutsopoulos HM, Balestrieri G, Bencivelli W, Bernstein RM, et al. Results of a European prospective multicentre study. Arthritis Rheum 1993;36: 340-7.

6 Segerberg M, Törnwall J, Sorsa T, Hietanen J, Konttinen YT. Neurotrophic factors in Sjögren' syndrome and acinar atrophy. In: Homma M, Sugai S, Tojo T, Miyasaka N, Akizuki M, eds. Sjögren's syndrome - state of the art. Amsterdam: Kugler Publications, 1994: 525-6.

7 Törnwall J, Konttinen YT, Tuominen RK, Törnwall M. Protein kinase $\mathrm{C}$ expression in salivary gland acinar epithelial cells in Sjögren's syndrome. Lancet 1997;349:1814-15.

8 Garret JR. The proper role of nerves in salivary secretion: a review. J Dent Res 1987;66:387-97.

9 Fox PC, van der Ven PF, Baum BJ, Mandel ID. Pilocarpine for the treatment of xerostomia associated with salivary gland dysfunction. Oral Surg Oral Med Oral Pathol 1986; 61: 243-8.

10 Greenspan D, Daniels TE. Effectiveness of pilocarpine in postradiation xerostomia. Cancer 1987;59:1123-5.

11 Fox PC, Atkinson JC, Macynski AA, Wolff A, Kung DS, Valdez $\mathrm{IH}$, et al. Pilocarpine treatment of salivary gland hypofunction and dry mouth (xerostomia). Arch Intern Med 1991;151:1149-52.

12 Johnson JT, Ferretti GA, Nethery WJ, Valdez IH, Fox PC, $\mathrm{Ng} \mathrm{D}$, et al. Oral pilocarpine for post-irradation xerostomia in patients with head and neck cancer. N Engl J Med 1993; in patients

13 Talal N, Quinn JH, Daniels TE. The clinical effects of electrostimulation on salivary function of Sjögren's syndrome patients. Rheumatol Int 1992;12:43-5.

14 Kelly JP, Dodd J. Anatomical organization of the nervous system. In: Kandel ER, Schwartz JH, Jessell TM, eds. Principles of neural science. 3rd ed. Norwalk: Appleton \& Lange, 1991: 273-82.

15 Konttinen YT, Platts LAM, Tuominen S, Eklund KK, Santavirta N, Törnwall J, et al. Role of nitric oxide in Sjögren's syndrome. Arthritis Rheum 1997;40:875-83.

16 Jenkins CD, Zyzanski SJ, Rosenman RH. Progress toward validation of a computer-scored test for the type A-coronary-prone behavior pattern. Psychosom Med

17 BMDP Statistical software manual. Berkeley: University of California Press, 1992

18 Snedecor GW, Cochran WG. Statistical methods. 7th ed. Iowa: The Iowa State University Press, 1980

19 Said SI. Vasoactive intestinal polypeptide: current status. Peptides 1984;5:143-50.

20 Hökfelt T, Johansson O, Ljungdahl A, Lundberg JM, Schultzberg M. Peptidergic neurons. Nature 1980;284: $515-21$.

21 Tatemoto K, Carlquist M, Mutt V. Neuropeptide Y - a novel brain peptide with structural similarities to peptide $Y Y$ and pancreatic polypeptide. Nature 1982;296:659-60.

22 Lundberg JM, Terenius L, Hökfelt T, Martling CR, Tatemoto K, Mutt V, et al. Neuropeptide Y (NPY)-like immunoreactivity in peripheral noradrenergic neurons and immunoreactivity in peripheral noradrenergic neurons and effects of NPY on sym $1982 ; 116: 477-80$.

23 Jänig W. Autonic Nervous System. In: Schmidt RF, Thews $\mathrm{G}$, eds. Human physiology, Berlin: Springer-Verlag, 1989: 333-70.

24 Konttinen YT, Kemppinen P, Segerberg M, Hukkanen M, Rees R, Santavirta S, et al. Peripheral and spinal neural mechanisms in arthritis, with particular reference to treatment of inflammation and pain. Arthritis Rheum 1994;37: $965-82$

25 Konttinen YT, Hukkanen M, Kemppinen P, Segerberg M, Sorsa T, Malstrom M, et al. Peptide-containing nerves in labial salivary glands in patients with Sjögren's syndrome. Arthritis Rheum 1992;35:815-20.

26 Boman B. Stress and heart disease. In: Fisher S, Reason J, eds. Handbook of life stress, cognition and health. New York: John Wiley, 1988: 301-15.

27 Fisher S. Life stress, control strategies and the risk of disease: a psychobiological model. In: Fisher S, Reason J,
eds. Handbook of life stress, cognition and health. New York: eds. Handbook of life stress,

28 Matthews KA. Psychological perspectives on the type A behavior pattern. Psychol Bull 1982;91:293-323.

29 Cox T. Psychobiological factors in stress and health. In: Fisher S, Reason J, eds. Handbook of life stress, cognition and health. New York: John Wiley, 1988: 603-27.

30 Lazarus RS. Psychological stress and the coping process. New York: McGraw-Hill, 1966.

31 Dodd J, Role LW. The autonomic nervous system. In: Kandel ER, Schwartz JH, Jessell TM, eds. Principles of neural science. 3rd ed. Norwalk: Appleton \& Lange, 1991: 761-75.

2 Said SI. Vasoactive intestinal peptide. J Endocrinol Invest 1986;9:191-200.

33 Törnwall J, Konttinen YT, Hietanen J, Sorsa T, Hukkanen $M$, Uusitalo H. VIP in salivary glands in Sjögren's syndrome. Br J Rheumatol 1995;34:891-3. 